\title{
Moving home in the early years: what happens to children in the UK?
}

\author{
Ludovica Gambaro University College London, Institute of Education \\ L.Gambaro@ioe.ac.uk \\ Heather Joshi University College London, Institute of Education
}

(Received September 2015 Revised February 2016)

http://dx.doi.org/10.14301/llcs.v7i3.375

\begin{abstract}
Children's early years are a time when many families move home. Does residential mobility affect children's wellbeing at age five in terms of cognitive and behavioural development? The question arises as moving home is sometimes portrayed as a stressful life event adversely affecting child development, particularly if frequent. Other studies suggest a more mixed role for home moves, which may reflect good or bad changes in family circumstances. This paper first presents evidence from the first five years of the UK Millennium Cohort Study about who moved, how often and why. We find that many British families at this point in the life cycle move to improve the housing of a growing family. We then investigate the relationship between the number of moves and child outcomes. Generally, moving displays an adverse association with our three indicators of child development at age five. However the adverse association is statistically explained by changes in family structure, employment status, insecure housing tenure, and other controls for family vulnerabilities. Moving is better seen as sometimes a response to other family stressors. Differentiating moves in terms of their destination we find that moving into the $30 \%$ poorest areas, as well as 'failing' to move out of them, shows some adverse outcomes for children. After allowing for other associations with family disadvantage, also apparent in other studies of the Millennium Cohort, we find a small but significant disadvantage to living in low-income areas as well as moving within them.
\end{abstract}

\section{Keywords}

Residential mobility, area poverty, move quality, child development, early years, Millennium Cohort Study

\section{Introduction}

This paper presents large-scale evidence on moving home by young families in the UK, looking for signs of any impact on children while they are still in their early years. Residential mobility is of interest from various angles - the geographical distribution of the population, the flexibility of the labour market and of housing and other service provision, family dynamics over the life-course, as a cause and consequence of health conditions, and of differences between neighbourhoods. There are many interacting facets to an individual change of address. These are narrowed here to a focus on moves and outcomes in children's early years, before schooling dominates their environment, but in which developmental foundations with lifelong consequences are laid down (Heckman, 2000; Shonkoff \& Phillips, 2000).

Early childhood is one of the points in life where people often move home. For example, the UK 2001 Census indicates that one in five families with a new birth had moved in the prior 12 months. Residential mobility declined for older children, but was still at $10 \%$ among five year olds. Children's mobility, of course, reflects decisions made by their parents and indeed the mobility rate of preschoolers was very similar to that of adults aged 30 to 35 (Champion, 2005). The residential mobility 
literature has long highlighted the link between family formation and mobility, but by focusing on why people move it has largely ignored children (Dieleman, 2001). Demographers and developmental psychologists have paid more attention to children, but they have usually been concerned with school-age children and adolescents (Anderson, Leventhal, Newman \& Dupéré, 2014). Although it is important to enquire whether home moves at school age disrupt schooling and peer relations, this study is specifically focussed on pre-school years, and deliberately abstracts from these issues.

There are several reasons to think that residential moves are also significant events for younger children. First, well before starting school children spend an increasingly large amount of time outside their home with adults other than their parents (Shonkoff \& Phillips, 2000). Moving home can cut these ties. Second, families with very young children often rely on a local network of support. Again, moving can expose parents, and mothers in particular, to difficulties in accessing services or obtaining the help they need. The residential mobility of families with young children is also relevant to service delivery. In the UK, since the early 2000s, several policies for children under five, for example Sure Start and the Neighbourhood Nursery Initiative, have had a distinct spatial character, with investment targeted within the most deprived areas. Mobility can undermine these policy efforts, especially if it is the most vulnerable families who move out.

Early childhood is here seen as a distinct phase in life, when moving home is a common event, which affects the contexts with which young children regularly interact - the family, the home environment and the neighbourhood. We ask which families change home during children's first five years of life and what association there is between moving and child's outcomes. In addressing these questions, we examine a series of co-occurring events in children's lives as well as the nature of moves. To do so, we use longitudinal evidence from a single source, the UK Millennium Cohort Study (MCS) over the period 2001-2006 when these children reached the age of five, and when public policies to support young families were in their heyday (Stewart, 2013). The study was undertaken in parallel with the analysis of residential mobility in the contrasting context of US cities, recorded by the
Fragile Families and Child Wellbeing Study (FFCWS), and analysed by Beck, Buttaro and Lennon (2016, this issue). We conclude that whether moving home helps or hinders children to flourish depends on the 'quality' of the move and a host of circumstances surrounding it.

\section{Some relevant literature}

A vast literature from several disciplines about residential mobility concurs that, in both the US and UK, people tend to be more mobile in phases of the life cycle when they have, or are themselves, young children. In the normal course of events, growing families require more living space (Clark \& Onaka, 1983). At least one person moves when partnerships form, as well as dissolve. Moves are also associated with positive or negative changes in employment, and may be motivated by opportunities to improve housing or neighbourhood. Besides these regularities, moving patterns in the UK are different from those in the US, mainly because they are less frequent and the structure of housing tenure has been more favourably tilted towards social housing in the UK than is public housing in the US. We concentrate mainly on studies from the UK, as they are more relevant to our empirical analysis (see Beck et al., 2016, this issue, for further references to the US literature).

Moves of British working age households in the 1990s were typically local and infrequent (Böheim \& Taylor, 2002; Clark \& Huang, 2003), but not invariably. They tended to cover longer distances when triggered by changes of employer. There were high rates of mobility for private tenants and those initially overcrowded or dissatisfied with their neighbourhood; higher rates of mobility for the unemployed than the employed, and for families with children under rather than over six. Marital change was also seen to trigger moves. Frequent mobility may be an influence on the stability of partnerships as well as vice versa (Boyle, Kulu, Cooke, Gayle, \& Mulder, 2008). As described by Clark (2013 and 2016, this issue) moves have a multiplicity of motives and vary in the extent to which they are forced or voluntary, or realised as intended. Owner occupation tends to be a destination tenure, from which people seldom move out, while renting privately has tended to be transitional, associated with instability. There is particular interest in Britain in the relative 
immobility of social tenants (i.e. those who rent from local government authorities or not-for-profit housing associations), who may not be free to seek new accommodation further afield than their original provider. Cho and Whitehead (2013) show that the characteristics of individuals to whom such housing is allocated offer an alternative explanation for their not moving. As the social housing sector shrinks from the mid 2000s (as also reported in Lupton, 2016, this issue), it is increasingly catering to the more vulnerable. At the other end of the social spectrum, good schools are a magnet for moves by families in the UK (Gibbons \& Machin, 2006), in particular by relatively advantaged, homeowning parents of pre-school children in the MCS (Hansen, 2014b). This behaviour boosts house prices in favoured localities, and contributes to spatial socioeconomic segregation.

The topic of residential mobility is intertwined with that of neighbourhood. Mobility may be both a cause of differences between communities - via selective in- and out-migration - and a consequence - neighbourhood characteristics (like good schools) may attract in-moves, or (in the case, say, of high crime) may precipitate flight. Among the challenges facing the study of effects of location per se on individual health, development or behaviour are those of allowing for selection effects, and of allowing for the duration of individual exposure to a particular environment, for which information on mobility can help (Hedman, 2011; van Ham, Manley, Bailey, Simpson, \& Maclennan, 2013). Even if statistical indicators measure nothing more than the composition of the 'local' population, their use in the targeting of policies can be justified on grounds of practicality. New Labour policies in early years of the 2000s were dominated by the idea of bringing resources to the most disadvantaged areas (Lupton, Fitzgerald \& Fenton 2013), rather than incentivising people to move out of them. This contrasts with an approach that has been adopted in the US of moving disadvantaged families away from disadvantaged areas, as explored in the Gautreaux and Moving to Opportunity experiments, which implicitly assumed that individuals would have something to gain from being in a 'better neighbourhood' (Chetty, Hendren \& Katz, 2016; Rosenbaum, 1995). In the UK the idea of mobility as a policy lever is probably less acceptable.

A review of the literature on area effects on children's outcomes, primarily in the US, provides a number of estimates of clear, albeit small, neighbourhood differences beyond those explained by individual circumstances, although the mechanism behind them is poorly understood (Leventhal \& Brooks-Gunn, 2001; Sastry, 2012). In the UK context, where inequalities across areas are not as wide as in the US (Tunstall, 2005), an association has been found between the neighbourhood context, variously measured, and child outcomes but this is relatively minor compared to the association with the individual family material circumstances. McCulloch (2006) found that externalising behaviour problems among the offspring of the British 1958 cohort, assessed in 1991, showed a more robust association to their neighbourhood than internalising behaviour or cognitive scores. In the case of the school-age twins in the Environmental Risk (E-Risk) Study the apparent protective effect against anti-social behaviour of neighbourhood collective efficacy was found only in deprived areas (Odgers et al., 2009). The analysis of internalising and externalising behaviour of three year olds in the MCS (Flouri, Tzavidis \& Kallis, 2010) used a variety of information on small statistical areas from the official Indices of Multiple Deprivation (IMD), but concluded that the socioeconomic resources of individual families dominated the explanation of child mental health problems. Further analysis of problem behaviour in the MCS over ages three, five and seven (Flouri, Midouhas, Joshi, \& Sullivan, 2015), found some evidence that neighbourhood deprivation was a risk factor for behaviour problems, alongside family poverty and adverse life events. Their model also allowed for residential mobility implicitly as it contributed to the sum of 'adverse' events, though it was neither identified separately, nor screened on whether the event had been stressful. Families whose moves put them into another IMD decile were 'credited' with a changed exposure to neighbourhood conditions. Positive parenting buffered these albeit modest risks. An analysis of cognitive outcomes in the offspring of the 1958 cohort, assessed at ages ranging from four to 16 , found an independent association of neighbourhood poverty and the child's vocabulary only among children aged four to six, contrary to the expectation that it would be stronger for older children (McCulloch \& Joshi, 2001). Even here, as elsewhere, the size of the estimated 'effects' of local conditions was much smaller than those of 
family circumstances. Heilmann, Kelly, Stafford, and Watt (2013) used a cross-classified multi-level model of children aged seven surveyed in the MCS who had neither moved school nor home since age five and found that neighbourhood 'effects' in cognitive scores were dominated by school 'effects'.

There is also research specifically on the effects of moving home during childhood. A psychological literature includes moving home as at least a potentially 'adverse life event' for children as well as adults (Tiet et al., 1998). Jelleyman and Spencer (2008) provide a systematic review of 26 studies on the health outcomes of residential mobility in childhood, but the studies included come mainly from North America and mainly concern outcomes in mid childhood or adolescence. A common finding is a negative outcome of multiple (or 'high frequency') moves. In particular, a study of residential mobility across phases of childhood draws attention to the changes in family and neighbourhood context entailed by a move for the child's experience, and notes the tendency in the US of such contexts to deteriorate with the number of moves (Anderson, Leventhal, Newman, \& Dupéré, 2014). Clark (2016, this issue) adds to the US-based evidence of adverse outcomes, school drop-out in particular, from high frequency moving. Dong and colleagues (2005) however warn that apparent associations between childhood residential mobility and multiple health risks during adolescence and adulthood may reflect a hidden role of adverse childhood experiences. These were ascertained in Dong's study through retrospective questions. Chetty, Hendren and Katz (2016) have recently reported long-term gains in terms of adult earnings to people who moved to better areas as children, but their data do not include outcomes in childhood. Oishi and Schimmack (2010) report that long-term outcomes in adulthood of childhood residential mobility depend on the individual's personality type, extroverts being more likely to thrive.

There is also mixed evidence on the outcomes of mobility from Europe. Chen (2013) uses Swedish data and finds a robust relationship for lower educational attainment among adolescents with a history of residential mobility and not living in owner occupation. This is attenuated, but not eliminated, by parents' education and little affected by family income and wealth. In a long term, prospective follow up of moves in childhood to ages
18 and 36 in the West of Scotland, Brown et al. (2012) found frequent moves, especially if they involved moving school, were associated with poorer outcomes in mental health and illegal drug use, even after adjusting for family circumstances. This was not found for physical health. Verropoulou, Joshi and Wiggins (2002) examined the relationship between moving home, family structure and children's wellbeing in the schoolaged children of the British 1958 cohort. In data collected in 1991, they found little to no association between moving home and children's cognitive attainment, or behaviour problems.

There have also been analyses of moves specifically among young children in the dataset we use here - the MCS. Moving in pregnancy or in the child's first nine months was associated with poor health in MCS mothers and their infants (Tunstall, Cabieses, \& Shaw, 2012). These authors were able to account for much of this by the family characteristics and the negative circumstances (such as a combination of partnership breakdown and homelessness) of some moves. However, changing address can potentially disrupt the relationships with health care providers. Pearce, Elliman, Bedford and Law (2008) found that moving was negatively associated with the uptake of childhood immunisations in MCS children up to age three. Moves between the first and second survey (when the cohort child went from nine months of age to three) were analysed by Flouri, Mavroveli and Midouhas (2013) in relation to behaviour problems at the second survey for both the cohort child and up to two older siblings aged four to 16 . Adjusting for family socioeconomic disadvantage at the first survey explained the association of moving with internalising problems but not with externalising problems. The latter remained significant even after accounting for change in family's socioeconomic disadvantage between waves, the level of local disadvantage and any change in it occasioned by a move.

Hence, the possible effects of moving home on children might be positive, negative, neutral, or reciprocal, depending on the outcome considered, the reason for the move and the circumstances and characteristics of the people making the move or staying put. Like the associations between child development and neighbourhoods, the association between moving and child outcomes in quantitative data is often statistically attributable to other 
factors, and the mechanisms behind causal effects, if any, remain poorly understood.

\section{The present study and our research questions}

We aim to extend the literature on residential mobility by turning attention to pre-school children. We look at mobility during early childhood and its association with cognitive and behavioural outcomes at age five. This also brings new findings and rich data to the study of child development. We build on the literature on residential mobility by examining those factors, such as partnership change and employment change, families' capabilities and initial housing circumstances, which may both explain mobility and directly account for variations in child outcomes. In particular, given the primacy of family environment for young children, we introduce a fine-grained classification of partnership changes and include an indicator of maternal depression alongside other socioeconomic control variables. We also take into account that residential mobility occurs within a context of neighbourhoods between which moves may be made. More precisely, we include a measure of poverty of the area of origin and that of destination to classify moves.

We explore evidence for effects of mobility on children in a changing national context. There is reason to suppose unfavourable moves by young families might have become more common, given the changes since the recession of 2008 and subsequent changes of government policy, as elaborated by Lupton (2016, this issue). Our research questions are:

1. Who are the families who make at least one move?

2. Is the number of moves made by family before a child was five associated with the outcomes we observe for children at that age?

3. Are these associations accounted for by other observed variables, including the level of poverty in the initial area?

4. Are moves to more or less advantaged areas associated with different child outcomes?

Before presenting the findings, we describe the data, variables and methods used.

\section{Data and definitions of variables}

We use data from the first three sweeps of the Millennium Cohort Study (MCS), a large-scale longitudinal study of children born in the UK between September 2000 and January 2002. Its clustered sample design oversamples areas (electoral wards) with high child poverty, high minority ethnicity (England), and the three smaller countries of the UK. The initial interviews (MCS1) were in 2001-2 when the cohort children were aged nine months. The second sweep (MCS2) was when the children were aged three, mostly in 2004, and the third (MCS3) around age five, mostly during 2006. There have been further follow-ups, not included in the present study. Altogether 19,244 families have been interviewed, including 692 missed at MCS1 ("New Families"). Around 15,000 responded at each of MCS2 and MCS3, not all the same people. For further information see www.cls.ioe.ac.uk/mcs and Hansen (2014a). We look only at the first child in families who had twins or triplets in the study. Although both parents were interviewed, where available, most of our information comes from the 'main respondent', in almost all cases the child's natural mother, who is for convenience referred to as 'mother'.

Our analytical sample includes 14,373 families who participated in MCS3 and for whom there is valid information on our three child outcomes (described below). In our analyses we use weights taking into account both the survey's complex sampling design and attrition up to sweep 3 (Plewis, 2007). However, we have not attempted to correct for biases introduced by excluding 873 families present at MCS3 with missing child outcome data. They were, for example, more likely to be living in disadvantaged areas.

For our multivariate analyses all variables with missing values in the analytic sample were imputed. Information on time-invariant characteristics was logically deduced from sweeps in which the respondent had participated. For all time-varying variables, imputations were carried out using a Markov-Chain-Monte-Carlo procedure with 20 imputations in Stata. Imputation allows us to retain two sets of families with valid child outcome information at MCS3 who had not participated at one of the two previous sweeps. One set is the "New Families", mentioned above (508 in the analytc sample) who were not present at sweep 1. The other is a substantial group in the original 
survey who did not respond at sweep 2 but who returned at sweep $3(1,277$ cases in the analytic sample). Not surprisingly, both groups were more likely to have moved than families present at all three sweeps. Indeed, residential mobility is a source of survey non-response generally, and in MCS (Mostafa, 2016, this issue; Plewis, Ketende, Joshi, \& Hughes, 2008). By not discarding observations missing at either wave 1 or 2 ("nonmonotonic attrition"), as well as using the attrition weights reflecting those absent from sweep 3, we have made an effort to minimize the bias from attrition.

\section{Outcome variables at age five}

The three indicators of child development at five are naming vocabulary, internalising behaviour problems and externalising behaviour problems.

The first indicator measures expressive language skills, an aspect of verbal cognitive ability. Assessment was made using the British Ability Scale (BAS) Naming Vocabulary subtest (Elliott, Smith, \& McCulloch, 1996). The test asks the child to name a series of pictures of everyday objects. The analysis uses standardised scores based on the normative BAS sample (Connelly, 2013).

The second and third indicators measure behaviour problems and are taken from a parental self-completed report on the Strengths and Difficulties Questionnaire (SDQ) (Goodman, 1997; see also www.sdqinfo.com ). These difficulties are not necessarily mutually exclusive. Internalising problems reflect how far children turn problems in on themselves, while externalising problems reflect their turning outwards ('acting out'). The internalising scale is the sum of subscales for emotional problems and peer problems. Examples of items in the two subscales are "Often seems worried" and "Tends to play alone". The externalising one combines the conduct problems and the hyperactivity subscales, with items such as "Fights or bullies other children" and "Constantly fidgeting". Both the internalising and externalising scales demonstrate good reliability, with Cronbach's alphas in the analytical sample of .66 and .79 respectively.

\section{Mobility}

Respondents were asked whether they had moved home between sweeps and we construct our mobility variables on the basis of their replies ${ }^{1}$. In our analyses we focus on mobility between MCS1 and MCS3. We do not take into account the nontrivial number of moves occurring in the nine months between the cohort member's birth and MCS1, for lack of information to model them precisely. We create two indicators of mobility: one binary, on whether or not the family reported any move between sweeps 1 and 3 ; and the other continuous, counting how many addresses they reported.

\section{Housing variables}

We look at two characteristics of housing: tenure and living space. Respondents are asked directly about the arrangement under which they occupy their home. We group their answers as follows: 1 . Social tenants, which includes both those renting from local authority and housing association; 2 . Private renters, whether or not they receive housing benefit, a government subsidy towards rent; 3. Home owners, which comprises outright owners, as well as those with a mortgage or partly owning and partly renting; 4. Other arrangements, which includes sharing with parents or living rent free. In relation to housing space, we use information on the number of rooms and the number of people living with respondents to create a binary indicator for overcrowding, defined as more than two people per room (Sabates \& Dex, 2015). ${ }^{2}$

\section{Local Area}

We approximate neighbourhood quality using a measure of the level of income poverty of residents in small areas. Small area is defined here, based on the statistical geography of the 2001 Census, as Lower Super Output Area (LSOA) in England and Wales; Datazone in Scotland; and Super Output Area in Northern Ireland. ${ }^{3}$ We use the income deprivation subscale of the first round of indexes of multiple deprivation (IMDs) for the four UK countries ((National Assembly for Wales (Statistical Directorate), 2005; Northern Ireland Statistics and Research Agency, 2005; Office of the Deputy Prime Minister, 2004; Scottish Executive (Office of the Chief Statistician), 2004). While the overall indexes differ slightly across countries, the income subscale does not. In all countries it is calculated as the ratio of people on means-tested benefit (including tax credits if below the poverty line) to the area population. We use the country-specific deciles of the income subscale included in the MCS dataset to construct a binary variable equal to 1 if the area is 
in the bottom three deciles, and 0 otherwise - a cutoff commonly used with IMDs. Because the deciles are country-specific, our multivariate analysis controls for UK country. Note that this sort of measure reflects the composition of the social environment of the area and, possibly, its rating in the housing market. It does not directly capture the quality of the services available nor the finer nuances of community processes that may be important to families with young children.

\section{Move Quality}

We attempted to assess whether the outcome of moving from the address at sweep 1 to the one occupied at sweep 3 constituted an improvement, deterioration, or no change in the quality of living accommodation, using information on both housing and area. However, after experiments with potential combinations of our variables on housing space, tenure and neighbourhood (described below), we operationalised 'quality of move' in terms only of dichotomising neighbourhood income within and above the bottom three deciles. We thus classified movers and stayers into six groups: 1 . Stayers in the better $70 \%$ areas; 2 . Movers within the better $70 \%$; 3. Movers into the better $70 \%$; 4 . Movers within the bottom 30\%; 5 . Movers into the bottom 30\%; 6 . Stayers in the bottom $30 \%$.

\section{Partnership changes}

We are interested in capturing changes in partnership status of the child's mother, as these may affect both mobility and child outcomes. We use information from cohort birth until the third interview and divide our sample into the following groups: 1 . Stably coupled ${ }^{4} ; 2$. Stably single (no partner); 3. From mother with biological father to mother with non-biological father; 4. From single mother to mother with father (whether biological of not); 5. From mother with biological father to single mother; Multiple transitions. ${ }^{4}$ Along with intact couples of biological parents, we also include a very small number whose cohort child is adopted

\section{Parental Employment transitions}

Movements in and out of employment have been shown to be associated with residential mobility. Here, these changes are taken into account at the family level. The family is deemed to be in employment if there is at least one parent in work at each one of the three surveys, and 'workless' if no parent has a job, be they a single parent or a couple. Their employment is summarised as follows: 1 .
Stably employed; 2 . Stably workless; 3 . Workless to employed (1 transition); 4. Employed to workless (1 transition); 5 . In and out of work (2 or 3 transitions). We have not attempted to record any further detail of the work histories, such as which parent of two was employed, in what type of work, but the net family income at MCS1 is taken into account separately. This allows us to differentiate between children whose families have different levels of earnings at baseline.

\section{Family demographics, health, and economic resources}

We allow that other facets of family circumstances, vulnerabilities and capabilities, may influence moving and also, either directly or indirectly, child outcomes. Our controls are family income (in logs), the size of the household, whether by age five the child has a new sibling, and maternal characteristics, such as education, ethnicity, whether born outside the UK, and indicators of her physical health and of depression ${ }^{4}$. We also take into account child characteristics correlated with development low birth weight, health problems, and birth order, and for measurement reasons, the child's exact age at the time of the assessment.

\section{Analytic Strategy}

Our analysis proceeds in two stages. The first investigates the predictors of moving in the period up to the survey at age five. The second stage models the outcomes for children at that age five survey, in terms of a cognitive score and internalising and externalising problems. Both mobility and child outcomes are analysed in relation to parental partnership and employment transitions occurring between the cohort child's birth and age five and also in relation to a set of controls for family vulnerabilities and capabilities measured at one point in time. In the first stage, we model mobility as a binary outcome and use a logistic regression to estimate the probability of making at least one move between the first survey at nine months and the third survey at age five. We prefer a binary indicator to a move count (as used by Beck, et al. 2016, this issue) because the proportion of families making repeated moves is small. Also, results do not vary substantially when modelling mobility as the number of moves using a negative binomial model.

The analyses of child outcomes are all conducted as linear regressions. We start with a modelling strategy that captures mobility by number of moves 
and introduces sequentially family transitions, employment transition, area and housing variables, and family vulnerabilities and capabilities (a similar strategy is adopted by Beck, et al., 2016, this issue). As it turns out that the number of moves is not much associated with child outcomes, we elaborate the information about those making any move in a different way - where moves ended up rather than how many were made. We attempt to distinguish the 'good moves' that are less likely to involve adverse outcomes for children, from 'bad moves', as discussed by Lupton (2016, this issue). After also looking at some other dimensions, our crude operationalisation of this distinction involves comparing the locations at nine month and age five surveys in terms of the level of income poverty of each area. We use $30 \%$ as cut-off to classify the poorest areas, but also checked the results against different cut-offs, as described below.

\section{Descriptive Statistics}

The mobility profile is presented in table 1 . The sample used here divides exactly 40:60 into families who moved between the nine month and age five surveys and those who did not, in terms of weighted percentages.

\section{Table 1. Home moves in the first three surveys of MCS}

\begin{tabular}{lrrr} 
& N & Weighted \% & St. Dev \\
\hline Moves between MCS1 and MCS3 (9 months to age 5) & & & \\
No move & 60.0 & $\mathbf{4 9 . 0}$ \\
No move since CM's birth & 52.7 & 49.9 \\
Moved between birth and 9 months & 7.2 & 25.9 \\
Any move & 40.0 & $\mathbf{4 9 . 0}$ \\
One move & 26.5 & 44.1 \\
Two moves & 8.6 & 28.0 \\
$\quad$ Three or more moves & & 4.9 & 21.7 \\
All & 14,373 & 100 & \\
\hline
\end{tabular}

Notes: Percentages are weighted for survey design and attrition. The sample size is the number of valid cases within the analytic sample. For 508 New Families, mobility status between sweep 1 and sweep 2 is deduced on the basis of their answers on the date moved to the current address. We replaced missing information (338) on the number of moves by attributing only one move to those who reported moving, and zero otherwise, thus slightly underestimating the true value.

Most - two thirds - of the movers (27\% of the cohort) moved only once, one in five movers moved twice, and only one in eight of them (5\% of the whole cohort) moved three or more times. This is about half the rate of mobility reported in the FFCWS cohort, reflecting the generally higher level of mobility for this age group in the US (Beck, et al., 2016, this issue). Around one in seven of the MCS movers covered long distances, over $50 \mathrm{~km}$, between the MCS1 and MCS3 surveys, while one in four moved less than one $\mathrm{km}$. When asked about reasons for the most recent move, the majority of MCS respondents cited positive attractions of a bigger house or better area, including, but not exclusively, for better schools. Negative reasons, such as family break-up, or problems with neighbours were mentioned very much less frequently. Only a very small number ( $1.4 \%$ of our sample) of MCS families experienced moves due to eviction, problems with landlord or inability to pay. It should be noted that this information is elicited after moving, once the respondent is interviewed at her new address. It is not surprising that so called "pull factors" - attractive characteristics of the new location - dominate responses, while "push factors" - negative features of the location of origin - are seldom reported. We were therefore unable to rely on this information to classify moves as 'good' or 'bad'. Likewise very few of the MCS moves involved homelessness. This is not surprising given that the time period covered by our window on MCS (2001-2006) was relatively prosperous, with a much more benign housing market than currently. A limitation of the data is that movers were not specifically asked if the move in question had been stressful, intended or regretted, as this would have been a better way to identify adverse events. Neither could we examine the effects of forced stays - families who could not move due to poor housing supply (see Lupton, 2016, this issue). 
Table 2. Whether the cohort family moved in the first 3 surveys: distribution of predictor variables and logistic regression estimates

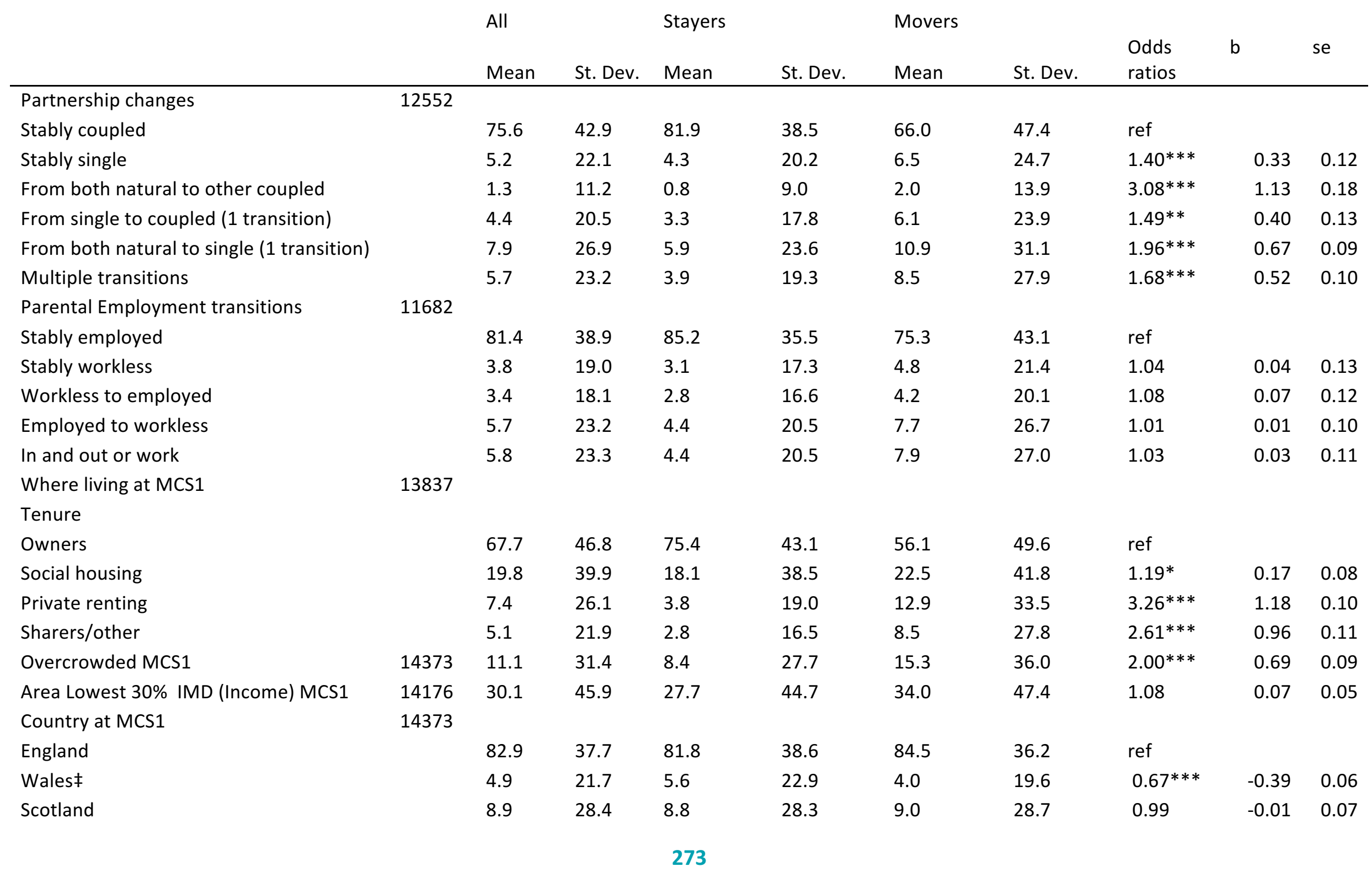


Northern Ireland

Family initial vulnerabilities and capabilities

Mother's age when child born (years) 13865

Child is oldest sibling (MCS1)

Child has younger sibling (MCS3)

Child had low birth weight

Child had health problems (MCS2) $\ddagger$

Mother depressed (MCS1)

Mother's general health (MCS1, score 1-

3)

Mother's highest qualification level

Family income (MCS1) (log $f$ /week)

Household size persons (MCS1)

Mother's Ethnic group

White

Indian $¥$

Pakistani and Bangladeshił

Black or Black British $\ddagger$

Other ethnic group $\ddagger$

Respondent not born in UK‡

13865
13865
14373
13831
13006
13851
13853
13829
13729
13865
14373

3.3

17.9

29.3

43.6

$$
5.7
$$

30.3

41.2

49.2

$6.4 \quad 24.5$

15.7

36.4

24.2

42.9

37.6

36.5

6.0

15.5

22.5

$\begin{array}{lll}2.2 & 0.7 & 2.2\end{array}$

2.2

$$
0.7
$$

\section{2}

$\begin{array}{ll}1.6 & 4.1\end{array}$

$\begin{array}{lll}5.6 & 0.7 & 5.7\end{array}$

3.9

1.1

4.0

$91.1 \quad 28.5 \quad 90.7$

$1.7 \quad 13.1 \quad 1.9$

$2.7 \quad 16.3 \quad 2.9$

$2.2 \quad 14.7 \quad 2.4$

$2.2 \quad 14.8 \quad 2.2$

Notes:

Means are percentages unless otherwise stated.

Difference in means between stayers and movers are significantly different at .05 level unless marked $\ddagger$ in row label.

Logistic regression carried out after multiple imputations (mi estimate command) using 14373 observations. Significance level of OR estimates: + p<.1; * $\mathrm{p}<.05 ; * * \mathrm{p}<.01 ; * * * \mathrm{p}<.001$. Overall model: $\mathrm{F}(32,384.9)=36.16$ Prob $>\mathrm{F}=0.000$ 
As shown in table 2 the majority (76\%) of MCS families in our sample had both biological parents present at all of the first three surveys, although the proportion of stable couples was smaller $(66 \%)$ for the movers, who correspondingly had more family transitions, the most frequent of which was one change from two biological parents to a one-parent family. Stability in employment was also the norm for both sets of families, but more so for the stayers, where $85 \%$ of the families had a least one parent in work at all three surveys, compared with $75 \%$ of the movers. Movers were more likely than stayers to have dropped out of work, once or more than once ( $8 \%$ each among movers; $4 \%$ each among stayers).

Two thirds of the families were in owner occupation at nine months (and also at age five), in line with the national statistics on housing tenure reported in Lupton (2016, this issue), but movers were less likely to own their home. The next biggest group were social tenants, constituting one fifth of the total sample at each point. The smaller categories - private renting and the rest (largely sharing accommodation) were also overrepresented among movers, as was overcrowding, and residence in disadvantaged areas.

We are using the event of a birth into the Millennium cohort to take a sample of families at an early stage of formation. The average age of mothers at that birth was 29.3 years. The stayers were over two years older than the movers, further along their life-course, and some had moved in the recent past. Many of the stayers had their first child before the cohort child (60\%). Over half of the cohort children among movers were first-born. The movers were also further behind in the family building process in that more of them had another child during the observation period than the stayers.

Our set of variables on health - low birth weight, child having a longstanding health problem reported at age three, mother's general health and mother's depression - all indicate on average poorer health among mover families.

We allow for the family's net income at the first survey and the highest level of education attained by the mother. There was little difference between the movers and stayers in terms of log equivalised household income. There was greater difference in their educational attainment, as mothers in the moving families averaged lower qualifications.
Around $9 \%$ of the families were assigned to nonwhite ethnic groups. Ethnic minorities tended to be under-represented among movers, as were immigrants to the UK.

In summary, the $40 \%$ of the parents who moved in this period were younger and more likely to be adding to their families. They also had fewer resources, as they were less likely to be owneroccupiers, less well educated, less healthy, and more likely to live in poor areas at first interview. Movers were also more likely to have changes in partnership and loss of employment than those whose address was stable

\section{Who are the families that make at least one move?}

The multivariate logistic model of making at least one move during the observation period reinforced some of these associations apparent in the bivariate comparison of movers and stayers. Families undergoing any sort of partnership change, or indeed having no partner throughout, were significantly more likely to move than intact couples, even when other factors are taken into account. Families where there was a change of partner had the highest relative odds of moving. Families with changes of employment status (or no employment throughout) were, by contrast, not significantly more likely to move than those with at least one parent employed throughout, once other circumstances were factored in. Owner-occupiers' low mobility and private renters' high mobility were confirmed. Those whose accommodation was overcrowded at MCS1 also show an independently raised rate of mobility, whereas the higher mobility of those sampled in poor areas was explained by other terms in the model.

The characteristics of a 'growing family' younger mother, the cohort child being the first born and not being the last - although all interrelated, each showed an independent association with the propensity to move. Household size, however, showed no association before or after modelling. Most of the features of the child's and mother's health, though significantly worse for movers in terms of means, did not make a significant contribution to the explanation in the multivariate model. The exception is the high propensity of depressed mothers to move ${ }^{5}$. Alongside family vulnerabilities, the multivariate analysis also reveals some markers of 
socioeconomic advantage - families with higher income and better educated mothers (especially graduates) have an underlying propensity to move.

Is the number of moves made by the family associated with worse child outcomes at age five?

On the face of it, the children whose families had moved had lower vocabulary scores, and somewhat more externalising and internalising behavioural difficulties than those who stayed put (as shown in table 3 ). This lends some support to the idea that moving might be a risk. That would be a premature conclusion before considering how many times those families had moved and the other ways in which the movers may have been at a disadvantage, including co-occurring changes, such as parental separation, which could impact child development and are more common among movers, as shown in table 2. We therefore report an exploration of the association of the number of moves between the first and third survey and child outcomes at age five. The rationale for this specification is to look for potential adverse effects of multiple moves, assuming that any move would be 'worse' than none.

Table 3. Child development outcomes at age five

\begin{tabular}{lrrrrrr} 
& \multicolumn{2}{c}{ ALL } & \multicolumn{2}{c}{ Stayers } & \multicolumn{2}{c}{ Movers } \\
& $\begin{array}{c}\text { Weighted } \\
\text { mean }\end{array}$ & \multicolumn{1}{c}{$\begin{array}{c}\text { St. } \\
\text { Dev. }\end{array}$} & \multicolumn{1}{c}{ Weighted } & \multicolumn{1}{c}{$\begin{array}{c}\text { St. } \\
\text { mean }\end{array}$} & \multicolumn{1}{c}{ Dev. } & Weighted \\
& mean & \multicolumn{1}{c}{$\begin{array}{c}\text { St. } \\
\text { Dev. }\end{array}$} \\
\hline Vocabulary z score & 0.552 & 1.06 & 0.582 & 1.07 & 0.507 & 1.05 \\
Externalising problems $(\max 20)$ & 4.64 & 3.35 & 4.5 & 3.27 & 4.9 & 3.45 \\
Internalising problems $(\max 20)$ & 2.40 & 2.44 & 2.3 & 2.38 & 2.54 & 2.51 \\
$\mathrm{~N}$ & 14,373 & & 8,709 & & 5,664 & \\
\hline
\end{tabular}

Naming Vocabulary taken from the second edition of the British Ability Scales (BASII; Elliott et al. 1996). A z score was created from the reference-population-age-adjusted scores using the mean and standard deviation of the normative scores from the standard BASII tables (Connelly 2013).

Internalising difficulties (emotional symptoms and peer problems) and externalising difficulties (hyperactivity and conduct problems) are each based on 10 items of the Strengths and Difficulties Questionnaire, each with 10 items each rated on a scale from 0 (best) to 2 (worst).

Table 4 summarises a series of regressions of number of moves on the three child outcomes at age five. Model 1 controls only, in addition, for the child's sex and exact age. There are significant estimates of worse outcomes for more moves. These are, per move, -0.044 standard deviations on the vocabulary score, and increases of 0.14 and 0.28 on internalising and externalising problem scores (or 0.058 and .059 respectively if the behaviour variables are also expressed in standardised $z$ scores). These estimates shrink in size and significance as sets of potentially competing explanatory variables are introduced. The allowance for the associated changes in family structure alone (model 2) reduces the estimate of moves on the verbal score to insignificance. This happens to the internalising score at the next model (3) when employment transitions are also introduced. The externalising score retains borderline significance as housing tenure, overcrowding and area at MCS1 are introduced, in model 4. Interestingly, the estimate of moves on the vocabulary score turns briefly positive at this point. None of the outcomes are significantly related to the number of moves when controls for the family's demographic, health and economic background are taken into account (model 5). 
Table 4. Estimated coefficients for number of moves in OLS regressions of child outcomes

\begin{tabular}{|c|c|c|c|c|c|c|}
\hline & \multicolumn{2}{|c|}{$\begin{array}{c}\text { Verbal } \\
\text { skills }\end{array}$} & \multicolumn{2}{|c|}{$\begin{array}{l}\text { Internalising } \\
\text { problems }\end{array}$} & \multicolumn{2}{|c|}{$\begin{array}{c}\text { Externalising } \\
\text { problems }\end{array}$} \\
\hline & $\mathrm{b}$ & SE & $\mathrm{b}$ & SE & $\mathrm{b}$ & SE \\
\hline Model 1: Only sex and age controlled & $-0.044 * * *$ & .012 & $0.140 * * *$ & .027 & $0.275^{* * *}$ & .034 \\
\hline Model 2: As model 1, with partnership transitions & -0.002 & .012 & $0.060 *$ & .027 & $0.104 * *$ & .032 \\
\hline Model 3: As model 2, with partnership and employment transitions & 0.012 & .012 & 0.039 & .027 & $0.079 *$ & .033 \\
\hline Model 4: As model 3, with housing tenure, overcrowding and area & $0.024 *$ & .012 & 0.020 & .026 & $0.061+$ & .032 \\
\hline Model 5: As model 4, with family demography, vulnerabilities and resources & 0.001 & .011 & 0.005 & .027 & 0.040 & 0.32 \\
\hline
\end{tabular}

Notes: OLS regression carried out after multiple imputations (mi estimate command) using 14,373 observations.

Significance level of OR estimates: $+p<.1 ; * p<.05 ; * * p<.01 ; * * * p<.001$. 
Although the externalising scores are most strongly associated with the small set of explanatory variables in model 1 , it was verbal skills that were most strongly predicted by the full set of variables in model 5 . Internalising behaviour showed the least 'sensitivity' to successive sets of explanatory variables.

The main point to emerge from table 4 is that generally speaking the poorer scores of children who moved are explained by the accompanying family events and circumstances. Moving may be part of the story leading to children's falling behind, but it appears the events and circumstances that lead to poor child outcomes, and may also lead to moves, are the main drivers of the disadvantages we found among children in moving families. Importantly, the same pattern of results emerges from the analysis of FFCWS by Beck et al. (2016, this issue).

\section{Do children have worse outcomes at}

\section{five if they have moved into 'worse places'?}

We return to the effects of the changes and circumstances below, but next turn to the question of whether we should be trying to distinguish between the sort of moves that bring advantage or disadvantage to children rather than a mere count of their number. Lupton (2016, this issue) draws attention to the notional distinction between 'good' and 'bad' moves. The challenge here is to operationalise a simple distinction of move quality that is not tautologically defined in terms of its outcome for children. We sought to distinguish between moves that themselves resulted in improvement or deterioration in the 'place' the family was living by the third survey. Since we do not have a complete history of every address occupied over the period, we compared the addresses occupied at the first and third surveys, in table 5 , on just three of the possible dimensions on which they could be rated: area, housing tenure, and living space 


\section{Table 5. Where living at age five}

\begin{tabular}{|c|c|c|c|c|c|c|c|c|}
\hline & & \multicolumn{2}{|c|}{ All } & \multicolumn{2}{|c|}{ Stayers } & \multicolumn{2}{|c|}{ Movers } & \multirow{2}{*}{$\begin{array}{l}\text { Sig of mean } \\
\text { diff movers } \\
\text { and stayers }\end{array}$} \\
\hline & & Mean (\%) & SD & Mean (\%) & SD & Mean (\%) & SD & \\
\hline Area at MCS3 Bottom 30\% Income IMD (as rated in 2001) & & 28.4 & 45.1 & 27.7 & 44.7 & 29.4 & 45.6 & ns \\
\hline Bottom $30 \%$ IMD both surveys & & 24.7 & 43.1 & 27.7 & 44.7 & 20.1 & 40.0 & \\
\hline Moved into Bottom IMD & & 3.5 & 18.3 & - & & 8.8 & 28.4 & \\
\hline Left Bottom IMD band & & 5.5 & 22.7 & - & & 13.9 & 34.6 & \\
\hline Better $70 \%$ both surveys & & 66.4 & 47.2 & 72.3 & 44.7 & 57.2 & 49.5 & \\
\hline \multicolumn{9}{|l|}{ Tenure at MCS3 } \\
\hline Owners & & 69.8 & 45.9 & 77.4 & 41.8 & 58.4 & 49.3 & $* * *$ \\
\hline Social housing & & 19.9 & 39.9 & 16.4 & 37.0 & 25.0 & 43.4 & $* * *$ \\
\hline Private renting & & 7.8 & 26.9 & 4.1 & 19.8 & 13.4 & 34.1 & $* * *$ \\
\hline Sharers/other & & 2.5 & 15.5 & 2.1 & 14.3 & 3.0 & 17.1 & $* *$ \\
\hline All & 14,370 & 100 & & 100 & & 100 & & \\
\hline \multicolumn{9}{|l|}{ Tenure at MCS3 BY tenure at MCS1 } \\
\hline Same tenure as MCS1 & & 83.0 & 37.6 & 92.5 & 26.4 & 68.7 & 46.4 & $* * *$ \\
\hline Became owners & & 7.11 & 25.7 & 4.34 & 20.4 & 11.31 & 31.7 & $* * *$ \\
\hline \multirow[t]{2}{*}{ Ceased to be owners } & & 3.9 & 19.4 & 1.32 & 11.4 & 7.8 & 26.9 & $* * *$ \\
\hline & 13,834 & & & & & & & \\
\hline Overcrowded MCS3 & & 4.8 & 21.3 & 5.0 & 21.9 & 4.4 & 20.5 & ns \\
\hline
\end{tabular}

Notes:

Significance level of difference in means: ${ }^{\dagger} p<.1 ;{ }^{*} p<.05 ;{ }^{* *} p<.01 ; * * * p<.001$. 
One type of residential change that might have led to adverse outcomes for children (over and above the other factors in the model) was the deprivation classification of the area. On our dichotomised summary of the income deprivation index, movers could have experienced one of four possible combinations and stayers could have remained in either the bottom $30 \%$ or the upper band. There are thus six possible values for the combination of areas at MCS1 and MCS3. A quarter of the cohort (weighted) overall were living in the deprived areas at MCS3, 20\% of the movers had moved within them, 9\% had moved 'down' into them, and more, $14 \%$ had moved 'up' into the better band.

There was less change in housing tenure: a small net increase in owner occupation by age five. This conceals some changes in tenure in all directions, mainly by the movers, but also including a shift of $2 \%$ of the stayers from social housing to owning, most likely through 'the right to buy'. Two thirds of the movers originally in social tenancies stayed in that tenure, with about one sixth becoming owners. One third of the private renters, and one tenth of those originally sharing or rent-free remained in their first tenure category if they moved. Although $86 \%$ of the owners who moved maintained their tenure, their moving out of this typically 'destination tenure' was highly correlated with adverse events such as partnership or employment loss. As a result, owner occupation at age five did not add to the explanatory models on child outcomes, and we did not include tenure change as an indicator of a possibly independently bad sort of move. Neither did we include housing space. Movers generally gained additional rooms, catching up with, or over-taking, the stayers, and recording even lower rates of overcrowding than the stayers. Overcrowding at MCS3 was not included in the regressions of child outcomes reported in table 6 as it was not significant ${ }^{7}$. As the quality of the move appeared to be captured mostly by the income deprivation of the area, we substituted the six-fold categorical variable for the numbers of moves tested in table 4's full model 5, leaving aside information on tenure or space.

Table 6. Estimated association of child outcomes with moving into and within the bottom $30 \%$ of areas between MCS1 and MCS3

\begin{tabular}{llllllllll} 
& \multicolumn{3}{c}{ Verbal skills } & \multicolumn{3}{c}{ Internalising } & \multicolumn{2}{c}{ Externalizing } \\
Problems & \multicolumn{3}{c}{ Problems } \\
& Coef. & Sig & SE & Coef. & Sig & SE & Coef. & Sig & SE \\
\hline
\end{tabular}

Type of move MC1-MCS3 by area change

Stayers in better $70 \%$ areas

Movers within better $70 \%$

$\begin{array}{llllll}-0.02 & 0.03 & -0.03 & 0.05 & 0.01 & 0.08 \\ -0.05 & 0.05 & 0.06 & 0.09 & 0.10 & 0.14 \\ -0.13 * * & 0.04 & 0.36 * * * & 0.09 & 0.37 * * & 0.12 \\ -0.03 & 0.06 & 0.04 & 0.14 & 0.01 & 0.20 \\ -0.10 * * & 0.04 & 0.12+ & 0.07 & 0.06 & 0.09\end{array}$

Movers into better $70 \%$

Movers within bottom $30 \%$

Movers into bottom $30 \%$

Stayers in bottom $30 \%$

Partnership changes (ref. stably partnered)

Stably single

0.01

0.06

0.23

0.15

$0.45 *$

0.19

From both biological to other coupled

$-0.02$

0.07

0.13

0.20

$1.63 * * *$

0.30

From biological to coupled (1 transition)

$-0.08$

$0.05 \quad-0.03$

0.15

$0.74 * * *$

0.17

From both biological to single (1 trans)

$-0.08 *$

0.04

0.10

0.10

$0.59 * * *$

0.13

Multiple transitions

$-0.01$

0.04

$0.22+$

0.12

$0.56 * *$

0.16

Parental employment transitions (ref. stably employed)

Stably workless

Workless to employed

Employed to workless
$-0.27 * * *$

$-0.04$

0.06

$0.64 * * *$

0.05

0.07

0.17

$0.61 * *$

0.21

$-0.05$

$0.34 * *$

0.15

$-0.17$

0.20

0.12

0.17

0.15 
In and out of work (2or 3 trns)

Where living at MCS1

Tenure (ref. Owner)

Social housing

Private renting

Sharing/other

Overcrowded at MCS1

Family capabilities and vulnerabilities

Mother's age when child born (years)

Child is oldest sibling (MCS1)

Child has younger sibling (MCS3)

Child had low birth weight

Child had health problems (MCS2)

Mother depressed (MCS1)

Mother's general health (MCS1, score 1-3)

Mother's highest qualification level)

Family income at first survey ( $\log f$ /week)

Household size persons (MCS1)

Mother's Ethnic group (ref White)

Indian

Pakistani and Bangladeshi

Black or Black British

Other ethnic group

Mother not born in UK

Country at MCS3 (ref. England)

Wales

Scotland

Northern Ireland

Child is male

Child's age in months (MCS3)

Constant

$\begin{array}{llllll}-0.12 * * & 0.04 & 0.19 & 0.12 & 0.01 & 0.16\end{array}$

$\begin{array}{rrrrll}-0.03 & 0.03 & 0.20^{*} & 0.09 & 0.50^{* * *} & 0.11 \\ -0.02 & 0.04 & 0.09 & 0.11 & 0.22 \dagger & 0.13 \\ 0.05 & 0.06 & 0.00 & 0.15 & 0.21 & 0.18 \\ -0.05 & 0.04 & -0.04 & 0.10 & -0.18 & 0.13\end{array}$

$\begin{array}{llllll}0.01 * * * & 0.00 & 0.00 & 0.01 & -0.04 * * * & 0.01\end{array}$

$\begin{array}{llllll}0.15 * * * & 0.02 & 0.43 * * * & 0.07 & -0.14 & 0.09\end{array}$

$\begin{array}{llllll}-0.03 & 0.03 & 0.19 * * * & 0.05 & 0.09 & 0.07\end{array}$

$\begin{array}{llllll}0.15 * * * & 0.04 & 0.43 * * * & 0.10 & -0.14 & 0.12\end{array}$

$\begin{array}{llllll}-0.08 * * & 0.03 & 0.32 * * * & 0.08 & 0.32 * * & 0.10\end{array}$

$\begin{array}{llllll}0.01 & 0.02 & 0.32 * * * & 0.06 & 0.32 * * * & 0.08\end{array}$

$\begin{array}{llllll}0.02 & 0.02 & -0.34 * * * & 0.04 & -0.45 * * * & 0.05\end{array}$

$\begin{array}{llllll}0.12 * * * & 0.01 & -0.14 * * * & 0.02 & -0.30 * * * & 0.03\end{array}$

$\begin{array}{llllll}0.15 * * * & 0.02 & -0.18 * * & 0.06 & -0.09 & 0.07\end{array}$

$\begin{array}{llllll}-0.07^{* * *} & 0.01 & 0.04 & 0.03 & -0.06 & 0.04\end{array}$

$\begin{array}{llllll}-0.24 * * & 0.09 & 0.43 * & 0.20 & 0.23 & 0.24\end{array}$

$\begin{array}{llllll}-0.69 * * * & 0.08 & 0.93 * * * & 0.19 & 0.35 & 0.22\end{array}$

$\begin{array}{llllll}-0.46 * * * & 0.08 & 0.16 & 0.15 & -0.25 & 0.22\end{array}$

$\begin{array}{llllll}-0.36 * * * & 0.07 & 0.29+ & 0.17 & -0.11 & 0.19\end{array}$

$\begin{array}{llllll}-0.17^{* * *} & 0.04 & 0.08 & 0.09 & -0.13 & 0.11\end{array}$

$\begin{array}{llllll}-0.14^{* * *} & 0.03 & -0.10 & 0.06 & -0.03 & 0.08\end{array}$

$\begin{array}{llllll}0.02 & 0.03 & -0.08 & 0.06 & 0.02 & 0.08\end{array}$

$\begin{array}{llllll}0.05 & 0.05 & -0.11 & 0.07 & -0.30 * * * & 0.08\end{array}$

$\begin{array}{llllll}-0.06 * * & 0.02 & 0.05 & 0.04 & 0.94 * * * & 0.05\end{array}$

$\begin{array}{llllll}-0.01 * & 0.00 & -0.02 * * & 0.01 & -0.05 * * * & 0.01\end{array}$

$\begin{array}{llllll}-0.25 & 0.29 & 5.09 * * * & 0.67 & 10.74 & 0.78\end{array}$

Notes: OLS regression carried out after multiple imputations (mi estimate command) using 14,373 observations.

Significance level of estimates: $+p<.1 ; * p<.05 ;{ }^{* *} p<.01 ; * * * p<.001$.

Within the majority living in the $70 \%$ better-off areas at MCS3, there was no difference in the child outcomes between those who had moved into these areas, moved within them or not moved at all, as shown in table 6 . The absence of any 'moving effect' was already familiar when no distinction was made by the geography of destination. For the families who had moved within the bottom $30 \%$ of areas, there was a significant deficit on all three outcomes in comparison with the reference group, stayers in the better $70 \%$ areas. In the case of externalising behaviour the coefficient of 0.37 on the SDQ score can be interpreted as an independent effect of moving. However for vocabulary, the stayers in the bottom $30 \%$ areas show almost as much of a mark-down on the $z$ score $(-0.10$, also significant) as the movers within these areas (-0.13), which looks more like an effect of living in poor areas than something attributable to the disruption of moving. For internalising behaviour there is a significant estimate for movers within these areas as for externalising and vocabulary. It seems that the generally propitious unmeasured circumstances that accompany many 
moves are more than outweighed by otherwise unobserved adversity if a move ends up in one of the disadvantaged areas. There is also some indication of an adverse association within poor neighbourhoods for families who do not move, and can perhaps be described as having failed to move out of them. The children whose families had moved into poor areas from elsewhere did not display significantly worse outcomes, perhaps because some of them had compensated for a downward move by improvements in living space.

We tested the robustness of these results by imposing different thresholds for the definition of 'poor areas' contrasting the bottom $20 \%$ with the top $80 \%$ and the bottom $40 \%$ with the top $60 \%$, rather than relying on the conventional $30 \%$ cut-off. In both of these versions, the estimates for an adverse effect of moving within the poorest areas were similar for all three outcomes. The adverse estimate for remaining at the bottom appeared significant for all three outcomes, for both alternative thresholds. Vocabulary showed deficits around -0.1 for children who had moved out of either the bottom $20 \%$ or $40 \%$ of areas, also negative but not significant when the threshold is set at $30 \%$ (table 6). These alternative versions on the whole reinforce the conclusion that the effects within disadvantaged areas are robust, reflecting some genuine disadvantage for children whose families live in poor areas, whether or not they move. Expressed in terms of standardised outcome scores, the contrast between moving within deprived areas and staying put in non-deprived areas is -0.13 for vocabulary, 0.15 for internalising, and 0.08 for externalising problems - neither negligible nor overwhelming in relation to other estimates in the model.

Our quest for other ways in which residential mobility may be related to child outcomes has also involved looking at the time elapsed since the last move at the age-five survey. Externalising behaviour was the only outcome to show any association (small) with moves in the last six months. Further attempts to identify recent moves that were also spatially unfavourable found few such events and no significant adverse effects. The possibility that moves may be more disturbing for older children has been investigated in the evidence collected on the older siblings of the Millennium cohort, so far inconclusively.
The estimated coefficients for controls in table 6 closely resemble those that were not shown in table 4 . They involve somewhat larger and more strongly determined coefficients than even the term for 'moving within poor areas'. They also vary by outcome. Partnership transitions are important independent predictors for externalising behaviour; employment transitions show adverse effects of persistent worklessness on all three outcomes, to an extent about twice of that estimated for moving within poor areas; social housing shows adverse associations for the behaviour outcomes, but not the verbal. Overcrowding at MCS1, though a powerful predictor of moving, showed no independent association with child outcomes. Older mothers have children with better vocabulary and fewer externalising problems. Cohort members with no older siblings do well on vocabulary but have more internalising problems, all else equal. Mother's depression is related to the two behaviour scores by about the same amount as moving within poor areas, but this may reflect the perception of the person reporting on behaviour (i.e. the mother) even though the depression was recorded several years previously. There are significant deficits on vocabulary for children in ethnic minorities at age five ${ }^{8}$. Family income is strongly related to the verbal score and also to internalising behaviour. The mother's education is a consistent predictor of child outcomes, just one rung higher on a seven-step ladder predicts about as much as avoiding being a mover within the bottom $30 \%$ for two out of three outcomes. The effects of moving are further put in perspective if one considers that family income, mother's age and education, and home ownership are positively correlated and estimates should be evaluated in combination to get an idea of the gap in child outcomes between prosperous and poor families. For example, the combination of having a mother with three steps up the education ladder (no qualifications to the middle level ' 3 ', or middle to a post-graduate qualification), plus an extra standard deviation of log income (roughly a doubling), plus living in owner occupation rather than social housing is predicted to raise the verbal score by nearly half a standard deviation (0.48) and reduce the behaviour scores by 0.73 and 1.45 points for internalising and externalising respectively (or just under one third of a standard deviation in each case). These are bigger orders of 
magnitude than the estimates for poor areas or for moving within them.

Thus the approach via quality of move in table 6 has been more successful at untangling a 'mobility effect' than the quantity of moves modelled in table 4 , but it is relatively small, and appears to be more a penalty affecting children who 'fail' to move away from poor areas, whether or not they move within them. These results therefore also contribute to the literature attempting to quantify contextual 'effects' on child outcomes.

\section{Conclusion}

We have looked at the correlates of British families moving home when they have a child under five in a longitudinal survey in the early 2000s. Moving was common for these growing families though not as common as in the US. We enquired whether the modestly lower average child development scores in families who moved meant that moving itself impeded children's progress, or whether these deficits could be accounted for by the other events and circumstances, as has tended to be found in literature on mobility and contextual effects on children.

Our main conclusion is that the five-year-olds in the UK Millennium cohort showed very little sign, in general, of a setback, on the outcomes observed, from family moves per se, over and above the formidable impact of other family changes and circumstances. We have been able to detect that moving adds to family stressors if it occurs within relatively deprived areas (echoing an earlier finding in another set of British data by Odgers et al., 2009). These areas also show poorer child outcomes for those who lived in them without moving home. Thus in the relatively poorer areas, particularly for vocabulary, we find an association with context almost as great as for mobility.

As these are observational data we cannot claim that these are true causal results of living and moving in deprived areas. We cannot rule out unobserved factors leading both to the location and the child outcome. We have however allowed for a number of potentially confounding factors in our rich dataset. Perhaps it is not surprising that our model in terms of a simple count of moves does not differentiate child outcomes. As we have seen, moves themselves vary in terms of housing destinations, the reasons families make them and the distances they cover. In the period our sample was observed, most moves were for better housing and or better location and covered sufficiently short distances to maintain a social network and contact with service providers. Few moves seem to have been forced. Family stresses were associated with poor child outcomes whether or not they involve a move, and whether or not the family lived in a disadvantaged area.

We repeat that our results are confined to children who moved during their early years and were assessed at age five. We therefore have no conclusions concerning development in later years or the experience of children who move home (and/or school) when they are at school age, but these have been investigated - with mixed results in other research, and the possiblity still remains of exploring these questions with the children of MCS and their older siblings. Another topic for future research is to draw a closer comparison between the UK MCS and the US Families and Child Wellbeing Study than is possible by just looking at the two articles in this issue.

Looking towards the subsequent period when the economy faltered, the labour market became less stable, the provision of social housing was shrinking, home ownership became less affordable and policies to support young families in cash and kind were being cut, it is likely that the number of young families moving home for negative reasons will have been increasing, as argued by Lupton (2016, this issue). It also seems unlikely that children will be spared adverse consequences of forced moves (Clark, 2016, this issue). But this study suggests that it is not only movers whose children's development may show the imprint of stresses and disadvantages. The 'stayers' who are in so many ways like the movers also show difficulties and deficits in their children's scores, which may even be exacerbated by not being able to move. Moving is neither an unambiguously adverse event, nor always a step forward, but it is a feature of family life. The public policies underpinning the early years, though increasingly stretched and localised, should be able to support families, both to take advantage of opportunities for good moves, and to avoid having to make bad moves. 


\section{Acknowledgements}

This work has been funded by ESRC grant ES/K000438/1 which enabled a collaboration with Mary Clare Lennon, Anthony Buttaro, and Brenden Beck at the Graduate Center, City University New York, with Ruth Lupton at the University of Manchester and with Tarek Mostafa at UCL IOE. We are grateful to them for their comments and support in the production of this paper. We are also grateful to the CLS data and survey management teams for their help in developing our dataset. We appreciate the contribution of the cohort families without whose co-operation this work would not have been possible.

\section{References}

Anderson, S., Leventhal, T., Newman, S., \& Dupéré, V. (2014). Residential Mobility Among Children: A Framework for Child and Family Policy. Cityscape: A Journal of Policy Development and Research, 16(1), 5-36.

Beck, B., \& Buttaro, A. Jr. and Lennon, M. C. (2016). Home moves and child well-being in the first five years of life in the United States. Longitudinal and Life Course Studies 7(3), 240-264. http://dx.doi.org/10.14301/llcs.v7i3.374.

Böheim, R., \& Taylor, M. P. (2002). Tied Down Or Room To Move? Investigating The Relationships Between Housing Tenure, Employment Status And Residential Mobility In Britain. Scottish Journal of Political Economy, 49(4), 369-392. http://dx.doi.org/10.1111/1467-9485.00237

Boyle, P., Kulu, H., Cooke, T., Gayle, V., \& Mulder, C. (2008). Moving and union dissolution. Demography, 45(1), 209-222. http://dx.doi.org/10.1353/dem.2008.0000

Brown, D., Benzeval, M., Gayle, V., Macintyre, S., O'Reilly, D., \& Leyland, A. H. (2012). Childhood residential mobility and health in late adolescence and adulthood: findings from the West of Scotland Twenty07 Study. Journal of Epidemiology and Community Health, 66(10), 942-950. http://dx.doi.org/10.1136/jech-2011-200316

Champion A (2005) Population Movement within UK, in Focus on People and Migration, ONS Chapter 6 , $92-113$

http://www.ons.gov.uk/ons/rel/fertility-analysis/focus-on-people-and-migration/december2005/index.html

Chen, J. (2013). Housing tenure, residential mobility and adolescents' education achievement: evidence from Sweden. The Annals of Regional Science, 50(1), 275-294. http://dx.doi.org/10.1007/s00168-011$\underline{0478-9}$

Chetty, R., Hendren, N., \& Katz, L. (2016) The Effects of Exposure to Better Neighborhoods on Children: New Evidence from the Moving to Opportunity Experiment, Americal Economic Review. 106, $(4$,$) 855-$ 902) http://dx.doi.org/10.1257/aer.20150572

Cho, Y., \& Whitehead, C. (2013). The immobility of social tenants: is it true? Does it matter? Journal of Housing and the Built Environment, 28(4), 705-726. http://dx.doi.org/10.1007/s10901-012-9331-4

Clark, W. A. (2016). Life events and moves under duress: Disruption in the life course and mobility outcomes. Longitudinal and Life Course Studies 7(3), 218-239. http://dx.doi.org/10.14301/llcs.v7i3.376.

Clark, W. A. V., \& Huang, Y. (2003). The life course and residential mobility in British housing markets. Environment and Planning A, 35(2), 323-339. http://dx.doi.org/10.1068/a3542

Clark, W. A. V., \& Onaka, J. L. (1983). Life Cycle and Housing Adjustment as Explanations of Residential Mobility. Urban Studies, 20(1), 47-57. http://dx.doi.org/10.1080/713703176

Connelly, R. (2013). Interpreting Test Scores Millennium Cohort Study Data Note 2013/1. London: Centre for Longitudinal Studies.

Dieleman, F. (2001). Modelling residential mobility; a review of recent trends in research, Journal of Housing and the Built Environment 16: 249-265. http://dx.doi.org/10.1023/A:1012515709292

Dong, M., Anda, R. F., Felitti, V. J., Williamson, D. F., Dube, S. R., Brown, D. W., \& Giles, W. H. (2005). Childhood residential mobility and multiple health risks during adolescence and adulthood: the hidden role of adverse childhood experiences. Archives of Pediatrics and Adolescent Medicine, 159(12), 1104-1110. http://dx.doi.org/10.1001/archpedi.159.12.1104 
Elliott, C. D., Smith, P., \& McCulloch, K. (1996). British Ability Scales Second Edition (BAS II). Administration and Scoring Manual. London: Nelson.

Flouri, E., Mavroveli, S., \& Midouhas, E. (2013). Residential mobility, neighbourhood deprivation and children's behaviour in the UK. Health \& Place, 20, 25-31. http://dx.doi.org/10.1016/j.healthplace.2012.12.002

Flouri, E., Midouhas, E., Joshi, H., \& Sullivan, A. (2015). Neighbourhood social fragmentation and the mental health of children in poverty. Health \& Place, 31, 138-145. http://dx.doi.org/10.1016/j.healthplace.2014.11.009

Flouri, E., Tzavidis, N., \& Kallis, C. (2010). Area and family effects on the psychopathology of the Millennium Cohort Study children and their older siblings. Journal of Child Psychology and Psychiatry, 51(2), 152161. http://dx.doi.org/10.1111/j.1469-7610.2009.02156.x

Gibbons, S., \& Machin, S. (2006). Paying for Primary Schools: Admission Constraints, School Popularity or Congestion? The Economic Journal, 116(510), C77-C92. http://dx.doi.org/10.1111/j.14680297.2006.01077.x

Goodman, R. (1997). The Strengths and Difficulties Questionnaire: A Research Note. Journal of Child Psychology and Psychiatry, 38(5), 581-586. http://dx.doi.org/10.1111/j.1469-7610.1997.tb01545.x

Hansen, K. (2014a). Millennium Cohort Study: A Guide to the Datasets. First, Second, Third, Fourth and Fifth Surveys (Eight ed.). London: Centre for Longitudinal Studies.

Hansen, K. (2014b). Moving house for education in the pre-school years. British Educational Research Journal, 40(3), 483-500. http://dx.doi.org/10.1002/berj.3092

Heckman, J. J. (2000). Policies to foster human capital. Research in Economics, 54(1), 3-56. http://dx.doi.org/10.1006/reec.1999.0225

Hedman, L. (2011). The Impact of Residential Mobility on Measurements of Neighbourhood Effects. Housing Studies, 26(4), 501-519. http://dx.doi.org/10.1080/02673037.2011.559753

Heilmann, A., Kelly, Y., Stafford, M., \& Watt, R. G. (2013). OP57 The Contribution of Neighbourhoods and Schools to Cognitive Test Performance at Age Seven - Findings from the UK Millennium Cohort Study. Journal of Epidemiology and Community Health, 67(Suppl 1), A28. http://dx.doi.org/10.1136/jech-2013-203126.57

Jelleyman, T., \& Spencer, N. (2008). Residential mobility in childhood and health outcomes: a systematic review. Journal of Epidemiology and Community Health, 62(7), 584-592. http://dx.doi.org/10.1136/jech.2007.060103

Leventhal, T. \& J. Brooks-Gunn. (2001). Changing neighborhoods and child well-being: understanding how children may be affected in the coming century. In Children at the Millennium: Where have we come from, where are we going?" vol. 6, pp263-301. http://dx.doi.org/10.1016/s1040-2608(01)80013-7

Lupton, R., A. Fitzgerald, \& A. Fenton. (2013). Labour's Record on Neighbourhood Renewal in England: Policy, Spending and Outcomes 1997-2010, Social Policy in a Cold Climate, Working Paper 6. London: Centre for Analysis of Social Exclusion, LSE.

Lupton, R. (2016). Housing Policies and their Relationship to Residential Moves for Families with Young Children. Longitudinal and Life Course Studies 7(3), 288-XXX. http://dx.doi.org/10.14301/llcs.v7i3.377.

McCulloch, A. (2006). Variation in children's cognitive and behavioural adjustment between different types of place in the British National Child Development Study. Social Science \& Medicine, 62(8), 18651879. http://dx.doi.org/10.1016/j.socscimed.2005.08.048

McCulloch, A., \& Joshi, H. E. (2001). Neighbourhood and family influences on the cognitive ability of children in the British National Child Development Study. Social Science and Medicine, 53(5), 579-591. http://dx.doi.org/10.1016/S0277-9536(00)00362-2

Mostafa, T. (2016). Measuring the Impact of Residential Mobility on Response: Evidence from the Millennium Cohort Study. Longitudinal and Life Course Studies 7(3), 201-217. http://dx.doi.org/10.14301/llcs.v7i3.378.

National Assembly for Wales (Statistical Directorate). (2005). Welsh index of multiple deprivation 2005. Technical Report. Cardiff: National Assembly for Wales. 
Northern Ireland Statistics and Research Agency. (2005). Northern Ireland Multiple Deprivation Measure. 2005. Belfast: Northern Ireland Statistics and Research Agency.

Odgers, C. L., Moffitt, T. E., Tach, L. M., Sampson, R. J., Taylor, A., Matthews, C. L., \& Caspi, A. (2009). The protective effects of neighborhood collective efficacy on British children growing up in deprivation: $A$ developmental analysis. Developmental Psychology, 45(4), 942-957. http://dx.doi.org/10.1037/a0016162

Office of the Deputy Prime Minister. (2004). The English indices of deprivation 2004 (Revised ed.). London: Office of the Deputy Prime Minister.

Oishi, S., \& Schimmack, U. (2010). Residential mobility, well-being, and mortality. Journal of Personality and Social Psychology, 98(6), 980-994. http://dx.doi.org/10.1037/a0019389

Pearce, A., Elliman, D., Bedford, H., \& Law, C. (2008). Residential mobility and uptake of childhood immunisations: findings from the UK Millennium Cohort Study. Vaccine, 26(13), 1675-1680. http://dx.doi.org/10.1016/j.vaccine.2008.01.031

Plewis, I. (2007). The Millennium Cohort Study: Technical report on sampling. London: Centre for Longitudinal Studies.

Plewis, I., Ketende, S. C., Joshi, H., \& Hughes, G. (2008). The Contribution of Residential Mobility to Sample Loss in a Birth Cohort Study: Evidence from the First Two Waves of the UK Millennium Cohort Study. Journal of Official Statistics, 24(3), 365-385.

Rosenbaum, J. (1995) 'Changing the Geography of Opportunity by Expanding Residential Choice: Lessons from the Gautreaux Program'. Housing Policy Debate, 6(1). http://dx.doi.org/10.1080/10511482.1995.9521186

Sabates, R., \& Dex, S. (2015). The Impact of Multiple Risk Factors on Young Children's Cognitive and Behavioural Development. Children \& Society, 29(2), 95-108. http://dx.doi.org/10.1111/chso.12024

Sastry, N. (2012). Neighborhood Effects on Children's Achievement: A Review of Recent Research. In R. B. King \& V. Maholmes (Eds.), Oxford Handbook on Child Development and Poverty (pp. 423-447). Oxford: Oxford University Press. http://dx.doi.org/10.1093/oxfordhb/9780199769100.013.0024

Scottish Executive (Office of the Chief Statistician). (2004). Scottish index of multiple deprivation 2004: technical report. Edinburgh: Scottish Executive.

Shonkoff, J. P., \& Phillips, D. (2000). From neurons to neighborhoods: the science of early child development. Washington, D.C. : National Academy Press.

Stewart, K. (2013). Labour's record on the under fivers: policy, spending and outcomes 1997-2010 Social Policy in a Cold Climate, Working Paper 4. London: Centre for Analysis of Social Exclusion, LSE.

Tiet, Q. Q., Bird, H. R., Davies, M., Hoven, C., Cohen, P., Jensen, P. S., \& Goodman, S. (1998). Adverse Life Events and Resilience. Journal of the American Academy of Child \& Adolescent Psychiatry, 37(11), 1191-1200. http://dx.doi.org/10.1097/00004583-199811000-00020

Tunstall, Rebecca (2005) Americans and Britons: key population data from the last three US and UK censuses. Census briefs: international Reports, CBIR/2. Centre for Analysis of Social Exclusion, The London School of Economics and Political Science, London, UK. http://eprints.Ise.ac.uk/51219/

Tunstall, H., Cabieses, B., \& Shaw, R. (2012). The characteristics of mobile families with young children in England and the impact of their moves on neighbourhood inequalities in maternal and child health. Health \& Place, 18(3), 657-670. http://dx.doi.org/10.1016/j.healthplace.2011.11.009

van Ham, M., Manley, D., Bailey, N., Simpson, L., \& Maclennan, D. (Eds.). (2013). Understanding Neighbourhood Dynamics: New Insights for Neighbourhood Effects Research. Dordrecht, Germany: Springer. http://dx.doi.org/10.1007/978-94-007-4854-5

Verropoulou, G., Joshi, H., \& Wiggins, R. D. (2002). Migration, family structure and children's well-being: a multi-level analysis of the second generation of the 1958 Birth Cohort Study. Children \& Society, 16(4), 219-231. http://dx.doi.org/10.1002/chi.700 


\section{Endnotes}

${ }^{1}$ Moves can also be inferred from the survey's address records. Information is generally consistent across the two sources, but there remain some discrepancies, mainly caused by changes of address that are not reported at interview. We decided to rely on self-reported information which allows greater consistency with other information collected in the interview (a similar approach is also taken by Beck, Buttaro and Lennon, this issue).

${ }^{2}$ The room total excludes halls, bathrooms, toilets, kitchen and one living room.

${ }^{3}$ LSOAs in England and Wales had a mean population around 1,600 in 2001; Datazones in Scotland, 800; and Super Output Area in Northern Ireland 2,000.

${ }^{4}$ Mother's depression is based on a question as to whether she had ever been diagnosed with depression or severe anxiety.

${ }^{5}$ We found in a separate analysis these mothers were also likely to have expressed dissatisfaction with their original neighbourhood at MCS1 but this term is not included in the model as we cannot say in which direction, if any, causation runs. 